\title{
A Study on HIV, Hepatitis B and Hepatitis C among Dental Patients Screened from Different Districts of Kashmir Valley
}

\author{
Sonia Gupta ${ }^{1}$, Suheel Hamid Latoo ${ }^{2}$ \\ ${ }^{1}$ Tutor, ${ }^{2}$ Associate Professor, \\ Department of Oral Pathology, Govt. Dental College \& Hospital, Srinagar \\ Corresponding Author: Sonia Gupta
}

\begin{abstract}
Background: Human immunodeficiency virus (HIV), hepatitis B virus (HBV), and hepatitis C virus (HCV) are the most common chronic viral infections worldwide. They are blood borne infections and share common routes of transmission, but they differ in efficiency by which certain types of exposures transmit them and their prevalence by geographic region.
\end{abstract}

Aims and objective: To evaluate the prevalence of HIV, hepatitis B and hepatitis C in patients screened from different districts, to increase the awareness among dental practitioners and the patients attending dental clinics as well as to evaluate the risk factors for infection with these viruses in order to reduce the burden of these diseases in the community.

Materials and method: A descriptive crosssectional study was carried out on 2150 subjects (1230 males and 920 females) reported in the Department of Oral Pathology, GDC \& H Srinagar for routine serological investigations. All the screened patients referred from different departments of this institution were enrolled.

Results: The prevalence of $\mathrm{HBV}$ and $\mathrm{HCV}$ among dental patients was $0.65 \%$ and $0.51 \%$ respectively but HIV positive cases had not been reported. In the present study, majority of the HBV positive cases were from Anantnag district and most common risk factors for infections were dental treatment and blood transfusion.

Conclusion: Prevention is an important aspect in controlling the spread of this viral infection as an epidemic. Hence, control programs for the prevention of these diseases that threaten public health must be planned and implemented.
Key words: Hepatitis B, HIV, Seroprevalence, Dental treatment, Transmission, Prevention

\section{INTRODUCTION}

Human immunodeficiency virus (HIV), hepatitis B virus (HBV), and hepatitis $\mathrm{C}$ virus (HCV) are the most common chronic viral infections worldwide. $^{1,2}$ Globally, chronic infection with each of these viruses alone contributes to substantial morbidity; HBV infection accounts for an estimated 370 million chronic infections, $\mathrm{HCV}$ infection for an estimated 130 million and HIV infection for an estimated 40 million. They are blood borne infections and share common routes of transmission, but they differ in efficiency by which certain types of exposures transmit them and their prevalence by geographic region. The main modes of transmission of HBV and HIV are from mother to child, horizontal in early childhood, unprotected sexual contact, sharing of sharps needles and injection drug abuse. HCV is transmitted mostly through direct contact with the blood of an infected person via blood transfusion and intravenous drug use. $^{2-4}$ The prevalence of mono-infection and co-infection is therefore common, especially in low- and middle-income countries in South-East Asia and Africa. ${ }^{4}$ The prevalence of chronic HBV infection is $<1 \%$ and the overall infection rate is $5-7 \%$. The estimated worldwide prevalence of 
$\mathrm{HCV}$ infection is $2.2 \%$ and $3.1 \%$ prevalence of HIV. ${ }^{5}$

$\mathrm{HBV}$ is a DNA virus that infects only humans and is highly contagious, more so than HCV or human immunodeficiency virus (HIV). Hepatitis $\mathrm{B}$ and $\mathrm{C}$ viruses are common causes of acute and chronic hepatitis. Human immunodeficiency virus and Hepatitis B have similar modes of transmission and hence co-infections are common and potentiate each other. HIV also increases risk of re-activation of previously existing asymptomatic and chronic HBV as well as HCV infections. Hepatitis B and C/HIV-co-infected individuals have a threefold risk of getting hepatotoxicity. Therefore proper diagnosis of HBV and HCV among HIV positive individuals is important and facilitates better management of patients. $5,6,1$

HIV, Hepatitis B and Hepatitis C are considered as an occupational hazard for dental professionals and other health care workers. Dentists and dental health care workers (DHCWs) are at a high risk of infection with HIV, HBV and HCV during their daily occupational experiences. Similarly, they can infect their patients by various agents if adequate infection control policies are not applied. In dental practice, infections can be spread through several routes, including direct or indirect contact with blood, oral fluids, droplet splatter, aerosols etc. ${ }^{7-9}$ In the occupational setting, exposures to contaminated needle sticks among healthcare workers have demonstrated that HBV is 100 times more infectious than HIV and HCV is 10 times more infectious than HIV. ${ }^{10}$ The present study was done to evaluate the prevalence of HIV, hepatitis B and hepatitis C in patients screened from different districts, to increase the awareness among dental practitioners and the patients attending dental clinics as well as to evaluate the risk factors for infection with these viruses in order to reduce the burden of these diseases in the community.

\section{MATERIALS AND METHOD}

A descriptive cross-sectional study was carried out on 2150 subjects (1230 males and 920 females) reported in the Department of Oral Pathology, GDC \& H Srinagar for routine serological investigations during the year 2018 to 2020 . All the screened patients referred from different departments of this institution for extractions, periodontal therapy such as scaling and root planning as well as other surgical procedures like diagnostic biopsy prior to oral and maxillofacial surgical procedures were enrolled. In the present study, no restriction to the patient for screening was done on the basis of age, gender and geographical distribution so as to confirm maximum participation of the subjects. Data was obtained by using direct interviewing questionnaire.

In the present study, $3 \mathrm{ml}$ of venous blood sample into plain tube were collected by venipuncture method in the antecubital fossa by using $5 \mathrm{ml}$ syringe to obtain serum by centrifugation at $5000 \mathrm{rpm}$ for 10 15minutes. Serum was screened for detection of hepatitis B surface antigen and hepatitis $\mathrm{C}$ antibody using the Rapid Card Diagnostic Test (SD Bioline rapid immunochromatographic test) along with detection of antibodies specific to HIV-1 and HIV-2 (Meriscreen HIV 1-2 WB) in human serum in all subjects. The data was analysed by using statistical software (SPSS version 21.0). Percentage and prevalence for all the variables were calculated.

\section{RESULTS}

A total of 2150 subjects reported in the Department of Oral Pathology, GDC \& $\mathrm{H}$ Srinagar for routine serological investigations during the year 2018 to 2020 . In the present study, $1230(57.2 \%)$ and 920 $(42.8 \%)$ were males and females respectively (Table 1). The age of the patients in this study ranged from 5-75 years but majority of the patients for screening were in the age groups of 16-30 years and 61-75 years (Table 2 ). 
The prevalence of $\mathrm{HBV}$ and $\mathrm{HCV}$ among dental patients was $0.65 \%$ and $0.51 \%$ respectively but HIV positive cases had not been reported in our study (Table 3). In $\mathrm{HBV}, 0.73 \%$ and $0.54 \%$ were males and females respectively; however seroprevalence of $\mathrm{HCV}$ in males and females were $0.49 \%$ and $0.54 \%$ respectively (Table 4).

In the present study, majority of the HBV positive cases were from Anantnag district $(64.3 \%)$ whereas $14.3 \%$ of HBV positive cases were from Srinagar and Kargil. In this study, $45.5 \%$ of the HCV positive subjects were from Anantnag (Table 5).

In the current study, $28.6 \%$ of the HBV positive cases showed risk factors like history of dental extraction, blood transfusion and idiopathic whereas $7.1 \%$ revealed history of surgery and family history. Regarding patients risk factors related to $\mathrm{HCV}$ positive cases, $36.3 \%$ and $27.3 \%$ showed history of blood transfusion and dental treatment whereas $9.1 \%$ cases revealed history of surgery, family history, prior blood disorders and idiopathic cause (Table 6).

Table1: Gender wise distribution of subjects

\begin{tabular}{|c|c|c|}
\hline Gender & Frequency & Percentage \\
\hline Male & 1230 & $57.20 \%$ \\
\hline Female & 920 & $42.80 \%$ \\
\hline Total & $\mathbf{2 1 5 0}$ & $\mathbf{1 0 0 \%}$ \\
\hline
\end{tabular}

Table 2: Age wise distribution of subjects

\begin{tabular}{|c|c|c|}
\hline Age (years) & Frequency & Percentage \\
\hline $5-15$ & 42 & $2.26 \%$ \\
\hline $16-30$ & 752 & $37.39 \%$ \\
\hline $31-45$ & 820 & $21.74 \%$ \\
\hline $46-60$ & 446 & $35.87 \%$ \\
\hline $61-75$ & 90 & $2.74 \%$ \\
\hline Total & $\mathbf{2 1 5 0}$ & $\mathbf{1 0 0 \%}$ \\
\hline
\end{tabular}

Table 3: Prevalence of seropositivity in patients

\begin{tabular}{|l|c|c|}
\hline Seropositive patient & Frequency & Percentage \\
\hline HBV positive & 14 & $0.65 \%$ \\
\hline HCV positive & 11 & $0.51 \%$ \\
\hline HIV positive & 00 & $00 \%$ \\
\hline
\end{tabular}

\begin{tabular}{|c|c|c|c|c|}
\multicolumn{4}{c}{ Table 4: Gender wise prevalence of seropositivity in patients } \\
\begin{tabular}{|c|c|c|c|} 
Seropositive \\
patient
\end{tabular} & Frequency & Percentage & Frequency & Percentage \\
\cline { 2 - 5 } & 09 & $0.73 \%$ & 05 & $0.54 \%$ \\
\hline HBV positive & 06 & $0.49 \%$ & 05 & $0.54 \%$ \\
\hline HCV positive & 00 & $00 \%$ & 00 & $00 \%$ \\
\hline HIV positive & 00 & \multicolumn{2}{c|}{ Females } \\
\hline
\end{tabular}

Table 5: Prevalence of seropositivity in patients by district (location)

\begin{tabular}{|c|c|c|c|c|c|c|c|}
\hline \multirow[t]{2}{*}{ District } & \multirow{2}{*}{$\begin{array}{l}\text { Total no. } \\
(n=2150)\end{array}$} & \multicolumn{3}{|c|}{ HBV positive $(n=14)$} & \multicolumn{3}{|c|}{ HCV positive $(n=11)$} \\
\hline & & $\mathbf{n}$ & $\begin{array}{c}\text { Percentage } \\
\text { (out of total } \\
\text { investigated cases) }\end{array}$ & $\begin{array}{c}\text { Percentage } \\
\text { (out of total } \\
\text { Positive cases) }\end{array}$ & $\mathbf{n}$ & $\begin{array}{c}\text { Percentage } \\
\text { (out of total } \\
\text { Investigated cases) }\end{array}$ & $\begin{array}{c}\text { Percentage } \\
\text { (out of total } \\
\text { positive cases) }\end{array}$ \\
\hline Srinagar & 1022 & 02 & $0.2 \%$ & $14.3 \%$ & 02 & $0.2 \%$ & $18.2 \%$ \\
\hline Anantnag & 580 & 09 & $1.6 \%$ & $64.3 \%$ & 05 & $0.9 \%$ & $45.5 \%$ \\
\hline Baramulla & 201 & 01 & $0.5 \%$ & $7.2 \%$ & 00 & $00 \%$ & $00 \%$ \\
\hline Pulwama & 187 & 00 & $00 \%$ & $00 \%$ & 02 & $1.1 \%$ & $18.1 \%$ \\
\hline Bandipora & 138 & 00 & $00 \%$ & $00 \%$ & 01 & $0.7 \%$ & $9.1 \%$ \\
\hline Kargil & 22 & 02 & $9.09 \%$ & $14.3 \%$ & 01 & $4.5 \%$ & $9.1 \%$ \\
\hline
\end{tabular}

Table 6: Risk factors associated with $\mathrm{HBV}$ and $\mathrm{HCV}$

\begin{tabular}{|l|c|c|c|c|}
\hline \multicolumn{1}{|c|}{ Risk factors } & \multicolumn{2}{c|}{$\begin{array}{c}\text { HBV positive } \\
\mathbf{n = 1 4}\end{array}$} & \multicolumn{2}{c|}{$\begin{array}{c}\text { HBC positive } \\
\mathbf{n = 1 1}\end{array}$} \\
\cline { 2 - 5 } & $\mathbf{n}$ & Percentage & $\mathbf{n}$ & Percentage \\
\hline History of dental treatment & 04 & $28.6 \%$ & 03 & $27.3 \%$ \\
\hline History of injections (IM or IV) & 00 & $00 \%$ & 00 & $00 \%$ \\
\hline History of surgery & 01 & $7.1 \%$ & 01 & $9.1 \%$ \\
\hline Family history (mother being a hepatitis carrier) & 01 & $7.1 \%$ & 01 & $9.1 \%$ \\
\hline Transfusion & 04 & $28.6 \%$ & 04 & $36.3 \%$ \\
\hline Tattooing & 00 & $00 \%$ & 00 & $00 \%$ \\
\hline Ear piercing & 00 & $00 \%$ & 00 & $00 \%$ \\
\hline Prior blood disorders & 00 & $00 \%$ & 01 & $9.1 \%$ \\
\hline Injury by contaminated needle & 00 & $00 \%$ & 00 & $00 \%$ \\
\hline Idiopathic & 04 & $28.6 \%$ & 01 & $9.1 \%$ \\
\hline
\end{tabular}

\section{DISCUSSION}

Viral hepatitis is a major public health problem occurring endemically in all areas of the world. An estimated 34 million people are currently infected with HIV worldwide and of these, three million are 
chronically infected with HBV and seven million are co-infected with HCV due to the similarity in the transmission routes. The prevalence of the disease is predisposed by several factors which may be able to modulate its onset. ${ }^{11}$

Dentists were in a high risk of contracting this disease due to the procedures and instruments of dental treatment. Dentists and their staff should know well about the risk of infection from their patients, the risk of cross-infection between patients and the risk of infecting each other. ${ }^{12}$ There have been studies showing the prevalence of hepatitis B surface antigen, hepatitis $\mathrm{C}$ antibody as well as HIV 1 and 2 antibodies in Kashmir valley. The present study was done to determine the prevalence of HIV, hepatitis $\mathrm{B}$ and hepatitis $\mathrm{C}$ in patients screened from different districts, to increase the awareness among dental practitioners and the patients attending dental clinics as well as to evaluate the risk factors for infection with these viruses in order to reduce the burden of these diseases in the community.

In the present study, the prevalence of $\mathrm{HBV}$ and $\mathrm{HCV}$ among dental patients was $0.65 \%$ and $0.51 \%$ respectively but HIV positive cases had not been reported during the study period, however, a previous study carried out in our department had reported that seroprevalence of $\mathrm{HBV}$ and $\mathrm{HCV}$ among dental patients was $4.4 \%$ and $4.3 \%$ respectively. ${ }^{13}$

In this study, seroprevalence of HBV in males and females were $0.73 \%$ and $0.54 \%$ respectively, whereas, seroprevalence of $\mathrm{HCV}$ were $0.49 \%$ and $0.54 \%$ in males and females respectively. In the previous study, the seroprevalence of $\mathrm{HBV}$ and $\mathrm{HCV}$ in males were $4.8 \%$ and $4.6 \%$ respectively, but in females, seroprevalence of both were similar (3.8\%). 13

In the current study, most of dental patients screened for HBV and HCV were from Srinagar district but majority of the $\mathrm{HBV}$ and $\mathrm{HCV}$ positive cases were from Anantnag district. These results were in accordance with study carried out by Latoo et al and Rehman et al. ${ }^{13,14}$ In this study, most of the HBV and HCV positive cases showed risk factors like history of dental extraction and blood transfusion. In the previous study, the prevalence of injection use both IV and IM was very high. ${ }^{13}$ In these patients, proper preventive measures must be adopted with strict protocol to prevent the transmission of the virus from the dental practitioner to the patient and from the patient to the dentist. Hepatitis can also have severe effects on the clotting ability of blood and other significant correlations along with extrahepatic oral manifestations. Therefore, preventive oral hygiene measures must be implemented to reduce the need for dental surgical treatments. Knowing facts, having proper awareness, proper behavior and attitude toward clinical aspects of the infection and toward the patients are critical to prevent the spread of these infections. ${ }^{15}$ Various health education programs should be conducted so as to prevent misconception and negative attitude against these disease.

The limitation of this study is that the study population is limited to dental patients and not for the general population. Hence, further screening in different cultural settings and on a larger sample size will be carried out so as to provide a better assessment regarding these diseases.

\section{CONCLUSION}

HIV, Hepatitis B and Hepatitis C are considered as an occupational hazard for dental professionals and other health care workers. Similarly, they can infect their patients by such agents if adequate infection control policies are not applied. Prevention is an important aspect in controlling the spread of this viral infection as an epidemic. Hence, control programs for the prevention of these diseases that threaten public health must be planned and implemented.

\section{Prior Publication: None}

\section{Support: None}




\section{Conflict of Interest: None \\ Permissions: None}

\section{Ethical Approval: Approved}

\section{REFERENCES}

1. Soriano, V.; Barreiro, P.; Nuñez, M. Management of Chronic Hepatitis B and C in HIV-Coinfected Patients. J Antimicrob Chemother 2006; 57 (5): 815-818.

2. Spada E, Mele A, Ciccozzi M, Tosti ME, Bianco E, Szklo A et al. Changing epidemiology of parenterally transmitted viral hepatitis: results from the hepatitis surveillance system in Italy. Digest Liver Dis 2001; 33:778-784.

3. Kourtis AP, Bulterys M, Hu DJ et al. HIVHBV co-infection-a global challenge. N Engl J Med 2012; 366(19):1749-1752.

4. Platt L, Easterbrook P, Gower E et al. Prevalence and burden of HCV co-infection in people living with HIV: A global systematic review and meta-analysis. Lancet Infect Dis 2016; 16(7):797-808.

5. Alter Miriam J. Epidemiology of viral Hepatitis and HIV Co-infection. J Hepatol 2006; 44 (1): S6-S9.

6. Yun-Fan L and Tung H. Chronic hepatitis B virus infection acquired in childhood, Taiwan. J Viral Hepatitis 2006; 14 (3): 147152.

7. Stewardson DA, Palenik CJ, McHugh ES and Burke FJ. Occupational exposures occurring in students in a UK dental school. Eur J Dent Educ 2002; 6:104-113.

8. Mahboobi N, Agha-Hosseini F, Mahboobi N, Safari S, Lavanchy D and Alavian SM. Hepatitis B virus infection in dentistry: a forgotten topic. J Viral Hepat 2010; 17: 307316.

9. Ahtone J, Goodman RA. Hepatitis B and dental personnel: transmission to patients and prevention issues. J Am Dent Assoc 1983; 106:219-222.

10. Wasley A, Alter M. Epidemiology of hepatitis C: geographic differences and temporal trends. Semin Liver Dis 2000; 20:1-16.

11. Freitas SZ, Soares CC, Tanaka TSO, Lindenberg ASC, Teles SA, Torres MS et al. Prevalence, risk factors and genotypes of hepatitis B infection among HIV-infected patients in the State of MS, Central Brazil. Braz J Infect Dis 2014; 18(5): 473-480.

12. Farghaly AG, Mansour GA, Mahdy NH, Yousri A. Hepatitis B and C virus infections among patients with gingivitis and adult periodontitis:seroprevalence and public health importance. Egypt Public Health Assoc.1998; 73(5-6):707-735.

13. Latoo S, Shafi $M$ and Nazir H. Seroprevalence of Hepatitis B and C virus among patients attending dental clinics in Kashmir Valley. IAIM 2017; 4(2): 53-59.

14. Rehman $S$ et al. Epidemic of Hepatitis $C$ in a remote village of Kashmir, India. EC Bacteriol Virol Res 2016; 2(1): 54-62.

15. Setia S, Gambhir RS and Kapoor V. Hepatitis B and C infections: clinical implications in dental practice. European $\mathrm{J}$ Gen Dent 2013; 2(1): 13-19.

How to cite this article: Gupta S, Latoo SH. A study on HIV, hepatitis B and hepatitis C among dental patients screened from different districts of Kashmir Valley. International Journal of Research and Review. 2021; 8(5): 19-23. DOI: https://doi.org/10.52403/ijrr.20210504 